\title{
URINARY EXCRETION OF NUCLEIC ACID DERIVATIVES IN PERSONS WITH MYELOID LEUKEMIA ${ }^{1}$
}

\author{
By DANIEL L. HORRIGAN \\ (From the Department of Medicine, Western Reserve University School of Medicine, \\ Cleveland 6, Ohio)
}

(Submitted for publication January 18, 1954 ; accepted February 17, 1954)

Considerable evidence has been presented to link growth and maturation of granulocytic leukocytes with cellular nucleic acid metabolism. The mechanisms of this relationship, however, remain unclear. Thus, Thorell (1), by microspectrophotometric techniques, has correlated the concentration of ribonucleic acid (RNA) present in the cytoplasm and nucleolus with growth potentialities of the blood cell. He showed that during maturation, cellular RNA concentration decreased progressively, paralleling the declining growth activity of the cell. Furthermore, he demonstrated the failure of rapidly proliferating cells in acute leukemia to show the rapid decline in RNA metabolism which is seen in normally proliferating cells following their active growth phase.

These differences in RNA content between immature and mature blood cells have been confirmed by Davidson, Leslie, and White (2). In this study, peripheral blood cells showed a significantly lower content of RNA phosphorus than bone marrow cells both in normal and in leukemic persons. However, decrease in the content of desoxyribonucleic (DNA) phosphorus in peripheral blood cells as compared with marrow cells was of borderline significance.

Further evidence relating cell growth with nucleic acid metabolism is found in the clinical response of some of the leukemias to substances, including folic acid antagonists, nitrogen mustards, urethane, cortisone and arsenic, which have been shown to inhibit biological synthesis of nucleic acid $(3,4)$. Furthermore, clinical observations by Vilter and his associates (5) relate the aberrant erythropoiesis in megaloblastic anemias with abnormal nucleic acid metabolism conditioned by deficiences of Vitamin $\mathrm{B}_{12}$ and folic acid.

1 This study was supported by a grant from the Montgomery County (Ohio) Society for Cancer Control and by the Price McKinney Fund.
Abnormalities in nucleic acid metabolism associated with aberrant cell growth in the leukemic organism might be reflected in the urinary excretion of intermediary products derived from these metabolic processes. In the present study, chromatographic and ultraviolet spectroscopic techniques have led to the identification of ultraviolet absorbing substances in the urine of persons with myeloid leukemia which are not present in the urine of non-leukemic subjects. One of these substances has been identified as uracil, a pyrimidine component of RNA.

\section{MATERIAL AND METHODS}

Five consecutive adult patients with myeloid leukemia admitted to the medical service of the University Hospitals of Cleveland served as subjects in this study. The peripheral blood hemograms of these patients at the time of this study are shown in Table I. Four of these (J. S., B. W., E. W., and J. McK.) presented a clinical diagnosis of chronic myeloid leukemia with peripheral leukocytosis, splenomegaly, anemia, and granulocytic hyperplasia in the bone marrow. The fifth patient (R. N.) was diagnosed as having leukemia of a myelomonocytic type. Although the peripheral leukocyte count of this patient was not greatly increased, abnormally young forms were noted in stained blood films; and the bone marrow showed marked leukocytic hyperplasia with 53 per cent blast forms.

Three patients (J. McK., E. W., and R. N.) had received no previous therapy. Patient J. S., had received two courses of splenic irradiation 16 and 10 months prior to this study. Patient B. W., had undergone a splenectomy elsewhere six years previous to this study. She had received radioactive phosphorus one year previously when a diagnosis of chronic myeloid leukemia was established. At the time of this study, hepatomegaly and adenopathy were marked and bone marrow biopsy revealed moderate myelofibrosis.

In addition, four non-leukemic patients on the medical wards of the hospital were studied as controls.

In order to minimize the urinary excretion of substances with ultraviolet absorption at wave lengths characteristic of nucleic acid derivatives (260-290 millimicrons), all subjects in the study were placed on an animal-protein-free diet with restriction of coffee, tea, and 
TABLE I

Peripheral blood findings in patients with myeloid leukemia

\begin{tabular}{|c|c|c|c|c|c|}
\hline Patient & J. S. & B. W. & E. W. & J. McK. & R. N. \\
\hline Sex & $\mathbf{M}$ & $F$ & M & M & $\mathrm{F}$ \\
\hline R.B.C. (Millions) & 2.64 & 2.74 & 2.49 & 3.34 & 2.64 \\
\hline Hgb. (Grams) & 6.7 & 8.4 & 6.5 & 10.0 & 8.0 \\
\hline W.B.C. & 440,000 & 131,000 & 318,000 & 85,000 & 13,000 \\
\hline$\%$ Neutrophils & 42 & 57 & 51 & 47 & 54 \\
\hline Metamyelocytes & 9.5 & 13 & 23 & 19 & 11 \\
\hline Myelocytes & 29.5 & 5 & 15 & 11 & 12 \\
\hline Eosinophils & 4.5 & 2 & 3 & 13 & - \\
\hline Basophils & 5.5 & 4.5 & 2 & 2 & 1 \\
\hline Monocytes & 0.5 & 7 & 2 & 4 & 10 \\
\hline Young Monocytes & - & 1.5 & 二 & 一 & 7 \\
\hline Blasts & 7.5 & 4.5 & 2 & 一 & 7 \\
\hline Lymphocytes & 1 & 5.5 & 2 & 4 & 8 \\
\hline Normoblasts per $100 \mathrm{WBC}$ & 6 & - & 2 & 4 & 1 \\
\hline
\end{tabular}

chocolate. After three days of this dietary restriction, 24-hour urine collections were made; three milliliters of concentrated hydrochloric acid were placed in each collecting bottle as a preservative. One one-hundredth of the total 24-hour urine volume was diluted tenfold with distilled water and the $\mathrm{pH}$ adjusted to 10 with concentrated ammonium hydroxide. Ultraviolet absorbing components in the urine were separated by collection of fractions in which absorption was increased according to the method of ion-exchange column chromatography described by Cohn (6). The diluted urine was passed through a column of anion exchange resin (Dowex-1, chloride form, bed size $12 \mathrm{~cm} . \times 1.77 \mathrm{~cm}^{2}$.). After washing to neutrality with water, the column was eluted with $0.003 \mathrm{~N}$ hydrochloric acid; this eluate was collected in $20 \mathrm{ml}$. fractions. The ultraviolet absorption of successive fractions was measured in a Beckman quartz spectrophotometer, Model DU, at a wave length of 260 millimicrons. These collections were then distilled to dryness in vacuuo at a temperature not exceeding $50^{\circ} \mathrm{C}$. The residue was redissolved in distilled water, $1.0 \mathrm{ml}$; $0.1 \mathrm{ml}$. of this solution was then spotted on a strip of
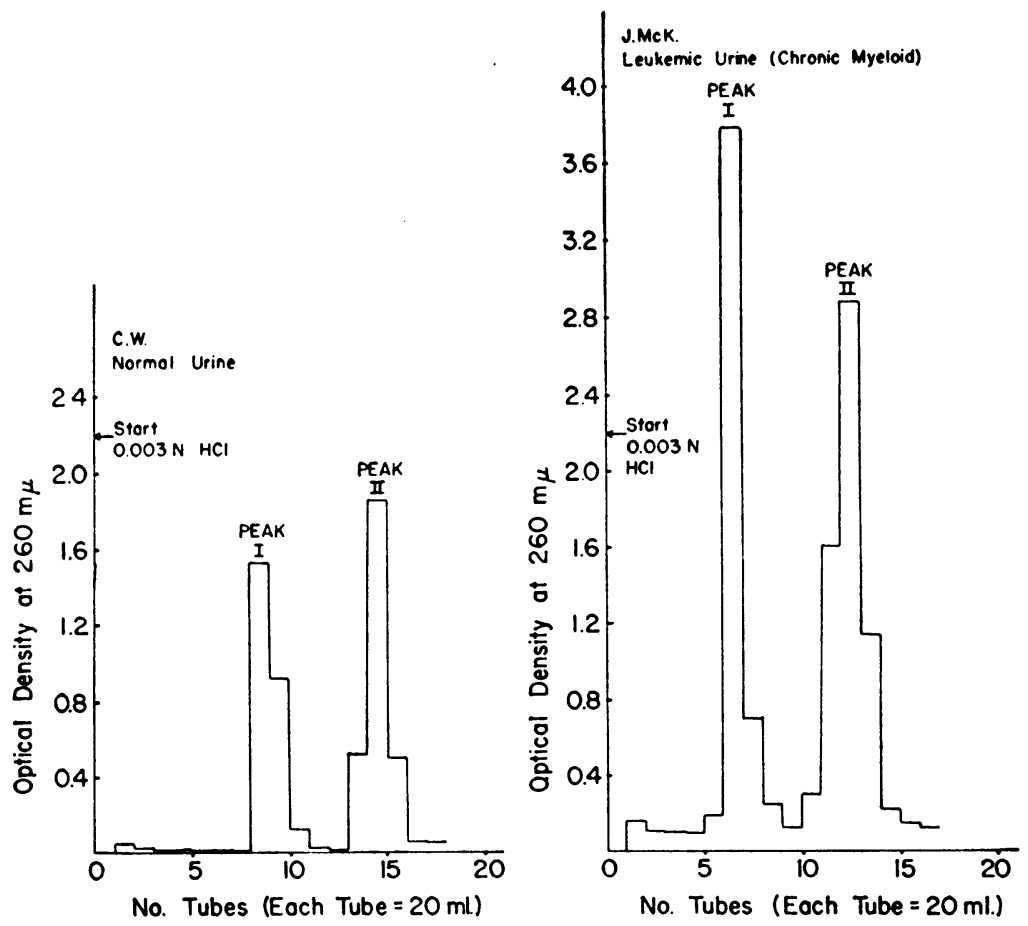

Fig. 1. Anion Exchange Separation of Substances in Normal (1a) AND MYeloid Leukemic (1b) Urine

Conditions for adsorption and elution are described in text. 
Whatman No. 1 filter paper for paper chromatographic studies. Ascending chromatograms were developed overnight using a 5 per cent $\mathrm{K}_{2} \mathrm{HPO}_{4}$-isoamyl alcohol mixture as solvent as described by Carter (7). After drying in air at $60^{\circ} \mathrm{C}$., component ultraviolet absorbing compounds were identified by exposure in the dark of the chromatogram to a source of ultraviolet light (Mineralight lamp, Model SL 2537). For spectral analysis, the spots were recovered from the chromatogram by cutting the areas showing absorption into small strips and eluting with water at $37^{\circ} \mathrm{C}$. overnight.

\section{RESULTS}

Representative diagrams of ultraviolet absorbing components in normal and leukemic urine eluted from the anion exchange column are seen in Figures $1 \mathrm{a}$ and $1 \mathrm{~b}$, respectively. Comparison of these two elution graphs shows in each instance the presence of two absorbing peaks, both of which are greater in the leukemic than in non-leukemic urine. The increased absorption of the first peak was seen in all five of the leukemic specimens examined (Table II), ranging in the leukemic urine from 5900 to 11,260 and in the normals from 3700 to $5480260 \mathrm{~m} \mu$ absorption units ${ }^{2}$ per 24 hours.

TABLE II

Quantitation of ultraviolet absorbing peaks recovered from anion exchange column chromatography of leukemic and non-leukemic urine

\begin{tabular}{|c|c|c|c|c|}
\hline \multirow{2}{*}{\multicolumn{2}{|c|}{ Patient }} & \multirow{2}{*}{$\begin{array}{c}\text { Peak I } \\
\text { Units* per } \\
24 \mathrm{hrs} . \\
(260 \mathrm{~m} \mu)\end{array}$} & \multicolumn{2}{|c|}{ Peak II } \\
\hline & & & $\begin{array}{l}\text { Units* per } \\
24 \mathrm{hrs} . \\
(290 \mathrm{~m} \mu)\end{array}$ & $\begin{array}{c}\text { Mg. uric } \\
\text { acidt per } \\
24 \text { hrs. }\end{array}$ \\
\hline $\begin{array}{l}\text { Myeloid } \\
\text { Leukemics }\end{array}$ & $\begin{array}{l}\text { J. S. } \\
\text { B. W. } \\
\text { E. W. } \\
\text { J. McK. } \\
\text { R. N. }\end{array}$ & $\begin{array}{r}7,280 \\
8,160 \\
11,260 \\
7,340 \\
5,900\end{array}$ & $\begin{array}{l}26,620 \\
44,930 \\
55,720 \\
34,165 \\
26,330\end{array}$ & $\begin{array}{l}458.9 \\
774.6 \\
960.6 \\
589.0 \\
454.0\end{array}$ \\
\hline Normals & $\begin{array}{l}\text { C. J. } \\
\text { D. H. } \\
\text { S. M. } \\
\text { C. W. }\end{array}$ & $\begin{array}{l}5,480 \\
4,950 \\
3,700 \\
4,900\end{array}$ & $\begin{array}{r}24,180 \\
20,140 \\
9,300 \\
13,360\end{array}$ & $\begin{array}{l}416.8 \\
347.2 \\
160.3 \\
230.3\end{array}$ \\
\hline
\end{tabular}

* See footnote 2 to text.

$\dagger$ See text for method of converting absorption units to milligrams.

Paper chromatography of this fraction in normal urines showed the development of one ultraviolet absorbing component with an $\mathrm{Rf}$ value of 0.78 (Figure 2). This component was also present in leukemic urines and gave a positive quali-

2 The number of absorption units was obtained by multiplying the volume of the effluent fraction by its optical density at the wave length specified. This value was then multiplied by 100 for the total 24 hour quantitation.

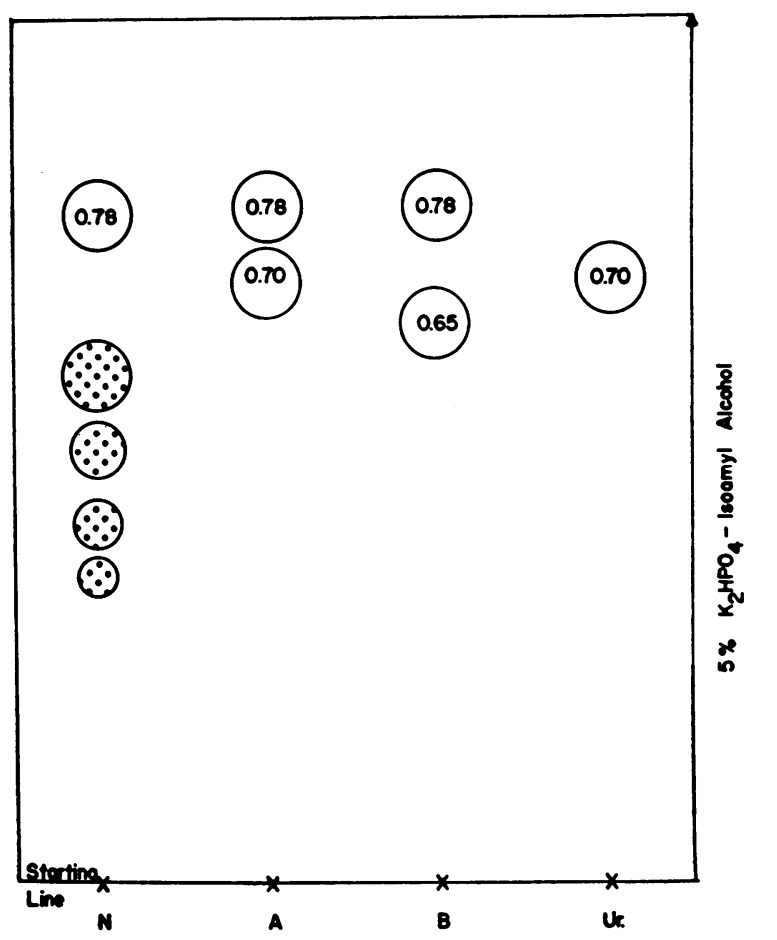

Fig. 2. Diagrams of Representative Paper Chromatograms of Peak I Urine Fractions

$\mathrm{Rf}$ values represented within each spot. $\mathrm{N}=$ Normal urine; $\mathrm{A}=$ Patients J. S., B. W., and R. N.; B = Patients J. McK., and E. W.; Ur = Uracil. Dotted areas represent fluorescent areas without significant absorption. Similar fluorescent spots are present in all chromatograms but are not included in the diagrams.

tative test for phenols (8). Four ultraviolet fluorescent spots were also developed; these did not show significant absorption, however.

In paper chromatograms of this fraction from three of the leukemic urines examined (Figure 2A), an ultraviolet absorbing substance with an $\mathrm{Rf}$ value of 0.7 was seen; this compound was not present in normal urine. In all three instances, the ultraviolet spectrum of this component was the same (Figure 3a) and was similar to that of uracil (Figure 3b). Also, this compound was similar to uracil in its paper (Figure 2, Ur) and anion exchange chromatographic properties. Furthermore, this substance supported growth ${ }^{3}$ for a yeast mutant Saccharomyces cerevisiae, reported by Pomper (9) to require uracil, uridine, uridylic acid, or 5 nitro uracil for growth. Of this group

3 The author is grateful to Dr. Irwin A. Rose, presently of the Department of Pharmacology, New York University, who performed these microbiological studies. 

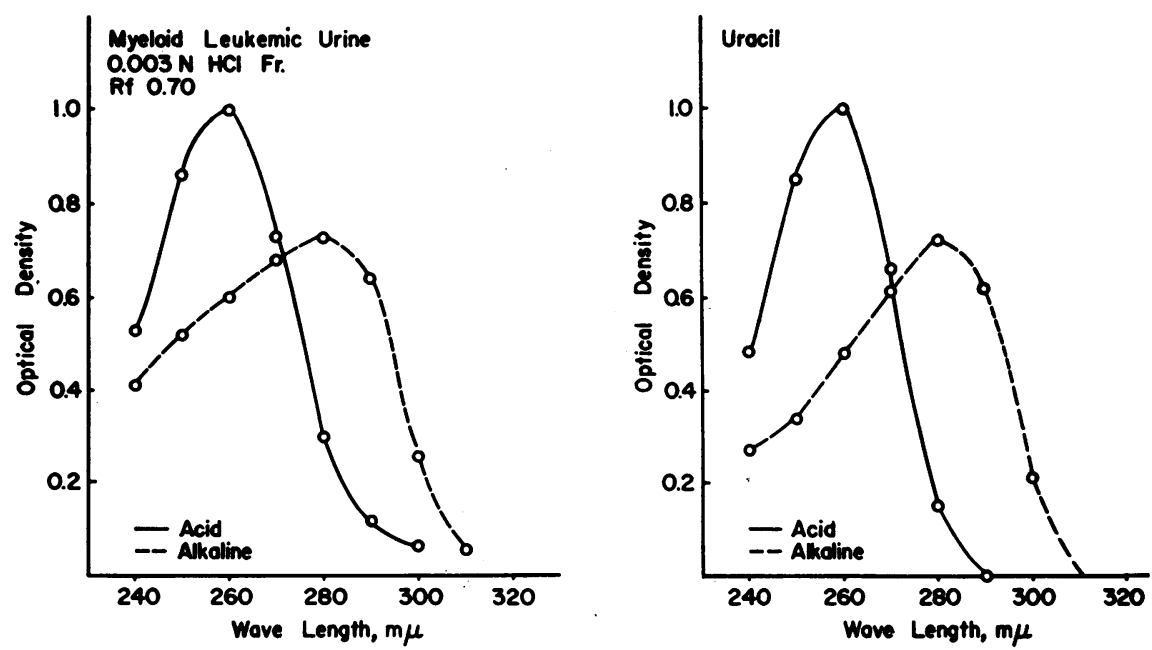

Fig. 3. Ultraviolet Spectrum of (a) Substance, Rf Value of 0.7, Isolated from Urine of Leunemic Patients, J. S., B. W. and R. N. and of (b) Uracil.

of substances, the spectral properties of this compound from leukemic urine identify it as uracil (10). Quantitation of the uracil excreted in the urine of two patients (R. N. and J. S.) showed a 24-hour excretion of $40.5 \mathrm{mg}$. in each patient (1.0 mg. uracil $=74$ absorption units at $260 \mathrm{~m} \mu$ ).

In similar paper chromatograms of this first fraction of urine specimens from the other two leukemic patients (Figure 2B), uracil was not found. However, in each instance a component with an $\mathrm{Rf}$ value of 0.65 was observed which was

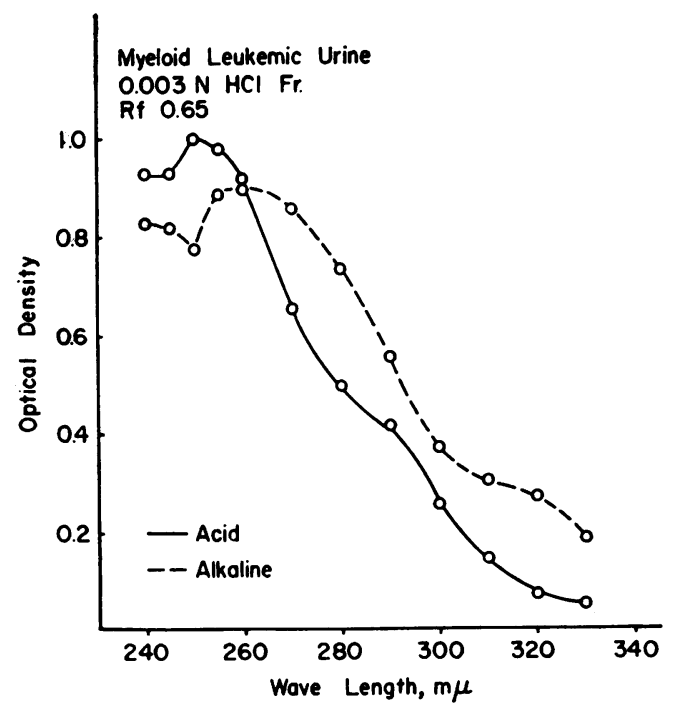

Fig. 4. Ultraviolet Spectrum of Substance, Rf Value of 0.65 , Isolated from Urine of Leukemic PaTIENTS J. McK. AND E. W. not present in normal urine. The ultraviolet absorption spectrum of this component was the same in both specimens and is recorded in Figure 4. Further, characterization of this component has not been accomplished. Nothing in the clinical evaluation of these patients was apparent to explain the presence of this different component in the urine of these two patients.

The second ultraviolet absorbing fraction of the elution diagrams (Peak II, Figure $1 a$ and $b$ ) in all specimens demonstrated maximum absorption at 290 millimicrons and represents uric acid. From the extinction coefficient of uric acid at this wave length $(1.0 \mathrm{mg}$. uric acid $=58$ units at 290 $\mathrm{m} \mu$ ), the 24-hour excretion of uric acid can be quantitated. These values are shown in Table II. Under the conditions of this experiment, the uric acid excretion in the four control subjects varied from 160.3 to $416.8 \mathrm{mg}$. per 24-hour urine specimen. In the five leukemic patients, the urinary excretion of uric acid varied greatly from patient to patient ranging from 458.9 to $960.6 \mathrm{mg}$. per 24 hours. In two of these (E. W. and C. W.) the elevation was marked, 960.6 and $774.6 \mathrm{mg}$. per 24 hours, respectively. In one (J. McK.), the elevation was moderate, $589.0 \mathrm{mg}$. per 24 hours. In the remaining two (J.S. and R. N.), the values, 438.9 and $454 \mathrm{mg}$. per 24 hours, respectively, were not greatly increased above those obtained in some normals. Again, there was nothing apparent in the clinical evaluations of these patients to explain 
these differences in uric acid excretion. Furthermore, the increased excretion of uric acid could not be correlated with the urinary excretion of uracil in this group of patients.

\section{DISCUSSION}

The presence of uracil in the urine of some persons with myeloid leukemia again brings attention to abnormalities in nucleic acid metabolism in this disease. Since uracil is a primidine component of RNA and not of DNA, this finding suggests the relationship of altered RNA metabolism to the abnormal growth and maturation of leukocytes in these patients.

The recent work of Caren and Morton (11) indicates that the metabolic fate of exogenous uracil in man involves rupture of the pyrimidine ring with excretion of most of its nitrogen as urea. However, work in this laboratory (12) has shown that a small amount of uracil is excreted as such when administered to normal persons. Thus, when two grams of uracil were given orally, about $126 \mathrm{mg}$. were recovered intact in the subsequent 24-hour urine collection.

The urinary excretion of uracil in some myeloid leukemics indicates its production endogenously in amounts which cannot be cleared by existing catabolic processes. Our present limited knowledge of nucleic acid metabolism in man, especially of the pyrimidines and their intermediates, permits only a speculative analysis concerning possible mechanisms for this increased endogenous uracil. The possibility exists that this is the reflection of increased destruction of immature cells, the RNA content of which is very high. However, the failure to recover thymine, a pyrimidine characteristic of DNA, seems against total cellular destruction as the mechanism. Furthermore, in two of the patients who excreted uracil (J.S. and R. N.), the excretion of uric acid did not reflect greatly excessive tissue destruction.

Other mechanisms which result in increased endogenous uracil might include (1) an extremely rapid turnover in RNA metabolism or (2) increased endogenous production of uracil which is not incorporated into cellular nucleic acid. The former explanation does not seem feasible in view of the high concentration of RNA present in leukemic cells $(1,2)$; and again. because of failure to demonstrate a proportional rise in uric acid excretion which would reflect increased breakdown of purine moieties of nucleic acid. Speculatively, the latter mechanism might imply some abnormality in the intermediary metabolism of pyrimidines. Further study is needed, however, for clarification of this as a possible metabolic aberration in these patients.

Increased endogenous uracil might also result from a deficiency in enzyme systems concerned in the catabolism of the pyrimidine ring to urea and oxalic acid. Uracil tolerance studies in normal and in leukemic persons now in progress in this laboratory may provide information concerning this as a possible mechanism.

The significance of the abnormal ultraviolet absorbing component recovered in patients $\mathrm{J}$. McK. and E. W. awaits further characterization of this substance. However, its presence in two leukemic patients and its absence in normals suggests some relationship to the leukemic process in these individuals.

\section{SUMMARY}

1. Abnormal ultraviolet absorbing substances have been identified in the urine of five patients with myeloid leukemia.

2. In three of these patients, the pyrimidine uracil has been identified spectroscopically, chromatographically, and microbiologically.

3 . In the other two patients, another substance. identified chromatographically and spectroscopically, was excreted; this substance has not been further characterized.

\section{ACKNOWLEDGMENTS}

The author gratefully acknowledges the assistance and encouragement of Dr. Charles E. Carter, presently Associate Professor of Pharmacology, Yale University School of Medicine. The preliminary experiments leading to this study were carried out in his laboratory in the Department of Medicine, Western Reserve University School of Medicine.

\section{REFERENCES}

1. Thorell, B., Studies on the formation of cellular substances during blood cell production. Acta med. Scandinav., Suppl. 200, 1947.

2. Davidson, J. N., Leslie, I., and White, J. C., Quantitative studies on the content of nucleic acids in normal and leukemic cells, from blood and bone marrow. J. Path. \& Bact., 1951, 63, 471. 
3. Skipper, H. E., Mitchell, J. H., Jr., and Bennett, L. L., Jr., Inhibition of nucleic acid synthesis by folic acid antagonists. Cancer Research, 1950, 10, 510.

4. Skipper, H. E., Mitchell, J. H., Jr., Bennett, L. L., Jr., Newton, M. A., Simpson, L., and Eidson, M., Observations on inhibition of nucleic acid synthesis resulting from administration of nitrogen mustard, urethan, colchicine, 2,6-diaminopurine, 8-azaguanine, potassium arsenite, and cortisone. Cancer Research, 1951, 11, 145.

5. Vilter, R. W., Horrigan, D., Mueller, J. F., Jarrold, T., Vilter, C. F., Hawkins, V., and Seaman, A., Studies on the relationships of vitamin $B_{12}$, folic acid, thymine, uracil, and methyl group donors in persons with pernicious anemia and related megaloblastic anemias. Blood, 1950, 5, 695.

6. Cohn, W. E., Some results of the applications of ionexchange chromatography to nucleic acid chem- istry. J. Cell \& Comp. Physiol., 1951, 38, Suppl. $1,21$.

7. Carter, C. E., Paper chromatography of purine and pyrimidine derivatives of yeast ribonucleic acid. J. Am. Chem. Soc., 1950, 72, 1466.

8. Folin, O., and Ciocalteu, V., On tyrosine and tryptophane determinations in proteins. J. Biol. Chem., 1927, 73, 627.

9. Pomper, S., Purine-requiring and pyrimidine-requiring mutants of Saccharomyces Cerevisiae. J. Bact., 1952, 63, 707.

10. Shugar, D., and Fox, J. J., Spectrophotometric studies of nucleic acid derivatives and related compounds as a function of $\mathrm{pH}$. I. Pyrimidines. Biochem. Biophys. acta, 1952, 9, 199.

11. Caren, R., and Morton, M. E., Pyrimidine metabolism in normal man studied with $\mathrm{N}^{15}$ labeled uracil. J. Clin. Endocrinol. \& Metab., 1953, 13, 1021.

12. Unpublished observations of the author. 